\title{
Static Test Study on Linear Induction Motor
}

\author{
Chandan Kumar, Member IACSIT
}

\begin{abstract}
Linear Induction Motors (LIMs) have got potential to replace the age old belt-pulley driven systems and the likes, which are in use for conversion of rotary to linear motion in most of the applications. In the present work a 3 phase Single sided longitudinal LIM $(50 \mathrm{~Hz}, 4$ pole, $440 \mathrm{~V}$, $9 \mathrm{KVA}$, and $52.4 \mathrm{~km} / \mathrm{hr}$ ) has been designed, fabricated and successfully tested on a test track in the Indian Railways Institute of Electrical Engineering Nasik (IRIEEN). In this paper the test results of the various standard experiments conducted on the machine are described.
\end{abstract}

Index Terms - linear induction motor, static test.

\section{INTRODUCTION}

This paper is an analysis of a live project on Traction application of Linear Induction Motor. The project has been an extension of the AICTE project in the department of Electrical Engineering, IT BHU [1]. This Project mainly deals with the practical description of the advantages of Linear Induction Motor Propelled (LIMP) Metro Train System, design of Linear Induction Motor for Traction Applications and the experimental observations and results that were obtained during the experiments performed over a live practical model of LIMP Metro Train System at Indian Railways Institute of Electrical Engineering, Nasik.

The experiments were performed under various practical conditions and changes were made in the system in order to practically obtain an optimal design of the model over which the experiments were carried on. The experimental data were obtained by changing the various parameters of the LIM such as air gap, magnetic gap, changing the materials of the secondary of LIM, by creating breaks in the electrical and magnetic circuits of the LIM, by de- aligning the primary with respect to secondary etc. by using different supply and controls. The tests were successfully conducted for direct voltage control, frequency control and variable voltage variable frequency control i.e. V/f control by using VVVF Drive and three phase auto Transformer. The data taken after experiments are plotted individually and relatively in order to compare the results under different situations.

Finally, the observations made and the graphs plotted have been explained and results successfully approved with the practical requirements for Traction Applications of Linear Induction Motor

\section{EXPERIMENTAL LAYOUT}

The tests were performed over a model of LIMP Metro

Manuscript received October 23, 2012; revised November 25, 2012.

C. kumar is with Powergrid Corporation of India Ltd. (PGCIL). He has completed his Bachelor of technology from Indian Institute of Technology, BHU, Varanasi, India in 2011. He is working in the field of PMUs and its applications. (e-mail: chandan.wrldc@yahoo.co.in)
System fabricated at IRIEEN, Nasik. The entire work was divided into two phases. In Phase-I, static tests were performed on the model. The static tests were sub-divided in various categories depending on the control strategies and possible abnormalities that the system may encounter in due course of time. In Phase-2, dynamic tests were performed and the data were recorded for speed, power, currents under different starting conditions and controls. In this paper, static tests are described and analyzed in detail and the performance of the model is analyzed on the basis of forces, power, starting power factor, starting current and different control strategies.

Static Test: Various tests were performed to simulate practical situations [2] are under mentioned:

1) Constant V/f control testing [3] by changing air gap between primary and secondary for different $\mathrm{V} / \mathrm{f}$ ratios.

2) Tests conducted by de-aligning primary with respect to secondary [4].

3) Tests performed by creating breaks in the secondary circuit of LIM. The breaks are created in the electrical circuit and magnetic circuit independently as well as simultaneously.

4) Voltage control testing for constant frequency of 50 $\mathrm{Hz}$

\section{SPECIFICATION OF LINEAR INDUCTION MOTOR}

The working model of Single Sided LIM is shown in Fig. 1.The short primary laminated core with conventional three phase windings, mounted under the carriage, and is in motion [4]. While the back iron capped with aluminium plate fastened to guideway, is the secondary part.

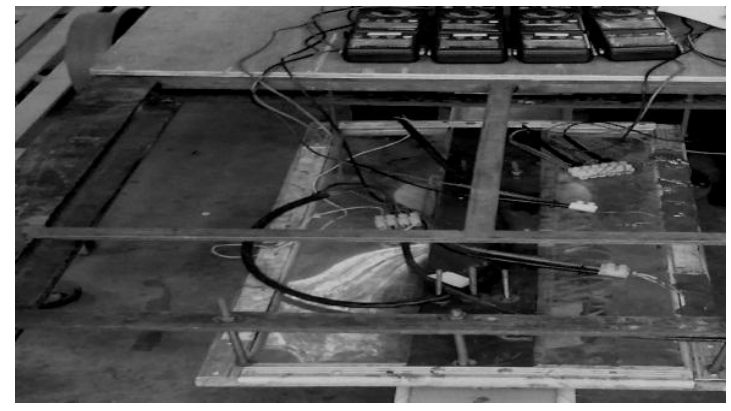

Fig. 1. Model of the LIM developed at IRIEEN, NASIK

To ensure safe operation, mechanical clearance between two parts is larger than that of the rotary motor. Magnetic flux excited by the primary windings passes through the airgap and nonferromagnetic aluminium plate and closes back by the back iron. Entry and exit ends exist due to finite primary length. The principal specifications for the studied LIM are shown in Table I. 
TABLE I: SPECIFICATION OF THE LIM

\begin{tabular}{cc}
\hline Parameters & Value \\
\hline Length of Primary $(\mathrm{mm})$ & 583 \\
Height of Primary $(\mathrm{mm})$ & 62 \\
Width of Primary $(\mathrm{mm})$ & 132 \\
Slot Width $(\mathrm{mm})$ & 10 \\
Tooth Width $(\mathrm{mm})$ & 6 \\
Slot Depth $(\mathrm{mm})$ & 35 \\
Slot Opening $(\mathrm{mm})$ & 6 \\
Rated Voltage $(\mathrm{V})$ & 600 \\
Rated Current(A) & 15 \\
Rated Frequency(Hz) & 50 \\
Rated Speed(Km/h) & 52.4 \\
Number of Phase & 3 \\
Number of Poles & 4 \\
Insulation class & $\mathrm{H}$ \\
Total No. of Slots & 33 \\
Slot Angular Pitch & $21.81^{\circ}$ \\
Phase Spread & $60^{\circ}$ \\
Coil Pitch & 6 \\
Number of Turns & 80 turns per coil \\
Type & Double Layer chorded Winding \\
\hline
\end{tabular}

\section{V/F CONTROL TEST}

The tests were carried out for V/f ratios of $6,8,9$ and 10 each under 3 different air gaps of $9 \mathrm{~mm}, 7 \mathrm{~mm}$ and $5 \mathrm{~mm}$ using ACS 600 VVVF Drive. Table II Shows the experimental data obtained for an airgap of $9 \mathrm{~mm}$. Fig. 2 and Fig. 3 show that with increase in V/f ratio from 6 to 9 , the propulsion force and input power also increases to good extent. The flux in the pole near operating frequencies remains almost constant as expected in the constant $\mathrm{V} / \mathrm{f}$ control. A boost-up in the flux density for small values of frequency is observed due to voltage boost up in the VVVF drive.

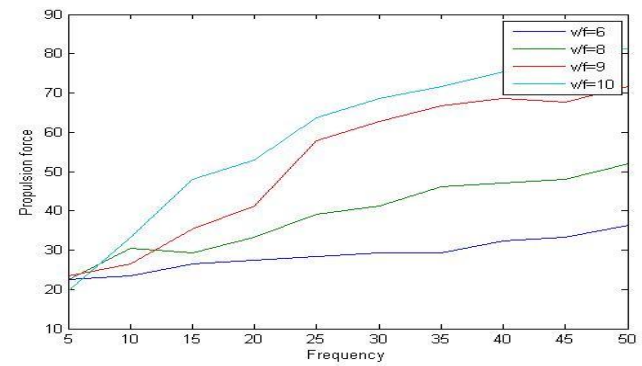

Fig. 2. Propulsion Force variation with frequency for different $\mathrm{V} / \mathrm{f}$

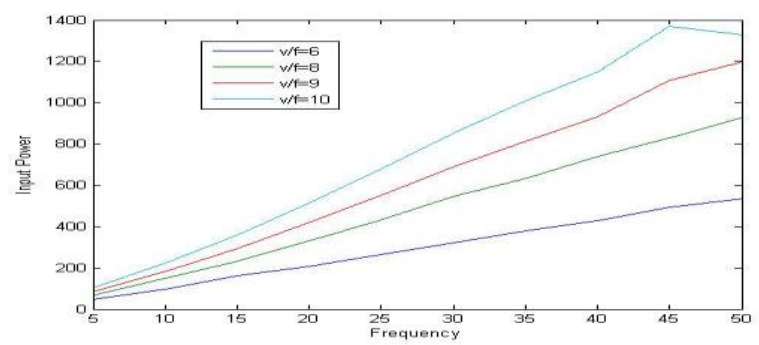

Fig. 3. Input Power variation with frequency for different V/f

For best starting, V/f control should be done starting at $25 \mathrm{~Hz}$ in order to avoid initial saturation due to voltage boost up. The tests were also performed at different air gaps mentioned and an air gap of $7 \mathrm{~mm}$ was found to be the optimal for system considered. Airgap of $5 \mathrm{~mm}$ is very tough to achieve and $9 \mathrm{~mm}$ lead to reduction in the force which makes them not suitable for our system.

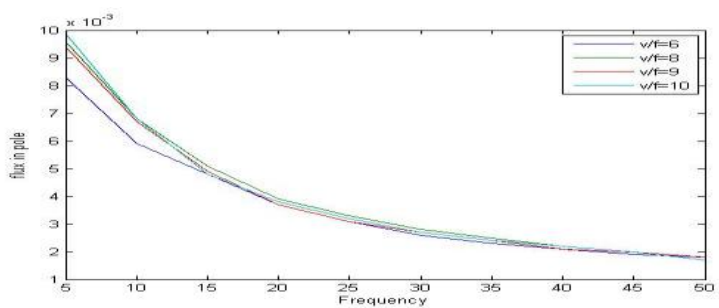

Fig. 4. Pole flux variation with frequency for different V/f

\section{De-Alignment Test}

The de-alignment tests are carried by de-aligning the LIM primary with respect to secondary in lateral direction [4]. This test is necessary in order to observe the effect of de-alignment produced on a curve track. De-alignment effect of $11 \%(15 \mathrm{~mm})$ and $25 \%(32 \mathrm{~mm})$ of primary with respect to secondary was observed on the Propulsion force and input Power for V/f ratio 9 with airgap of $7 \mathrm{~mm}$ and compared the result with the standard test. Table 2 shows the variation in force and power for these de-alignments.

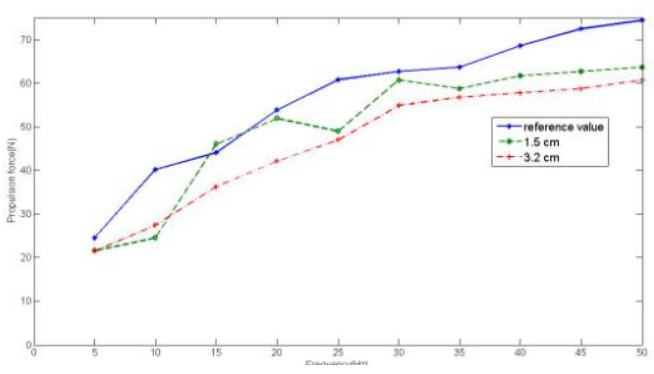

Fig. 5. Propulsion force variation with frequency for Dealignment

From the Fig. 5 it is observed that even up to $25 \%$ dealignment the propulsion force developed is quite healthy compared to reference for driving the locomotive. Hence, slight de-alignment at the turns will not be a major issue of concern. Also from Fig. 6 the change in Input Power Variation is small with the lateral shift. So we can go up to $25 \%$ de-alignment while making a curve for the secondary track when direction change is required.

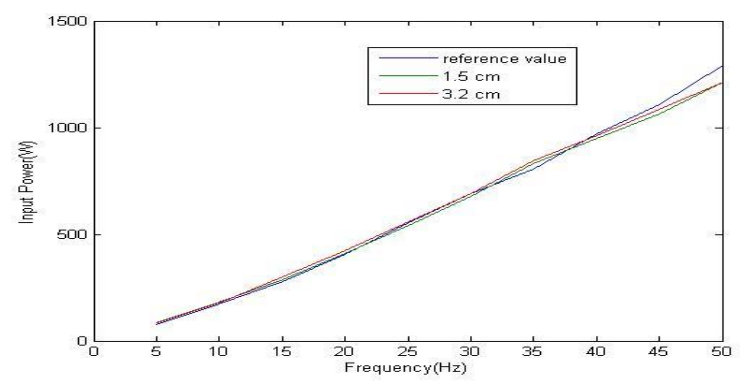

Fig. 6. Input power variation with frequency for Dealignment and reference value 
TABLE II: STATIC TEST RESULTS

\begin{tabular}{|c|c|c|c|c|c|c|c|c|c|c|c|}
\hline \multicolumn{2}{|c|}{ Frequency } & 5 & 10 & 15 & 20 & 25 & 30 & 35 & 40 & 45 & 50 \\
\hline \multicolumn{12}{|c|}{ Constant V/f Control Test (for an airgap of $9 \mathrm{~mm}$ ) } \\
\hline \multirow{3}{*}{$V / f=6$} & Force $(N)$ & 22.5 & 23.5 & 26.5 & 27.4 & 28.4 & 29.4 & 29.4 & 32.2 & 33.3 & 36.3 \\
\hline & Input Power $(W)$ & 47.19 & 95.59 & 163.35 & 206.91 & 264.99 & 323.07 & 377.52 & 427.3 & 492.47 & 536.03 \\
\hline & Flux in a Pole $(W b)$ & 0.92 & 1.30 & 1.60 & 1.66 & 1.71 & 1.75 & 1.80 & 1.86 & 1.90 & 1.95 \\
\hline \multirow{3}{*}{$V / f=8$} & Force $(N)$ & 22.5 & 30.4 & 29.4 & 33.3 & 39.2 & 41.2 & 46.1 & 47.0 & 48.0 & 51.9 \\
\hline & Input Power $(W)$ & 66.55 & 148.83 & 229.90 & 330.33 & 430.76 & 544.50 & 632.83 & 739.31 & 828.85 & 926.86 \\
\hline & Flux in a Pole $(W b)$ & 1.07 & 1.51 & 1.70 & 1.75 & 1.82 & 1.87 & 1.93 & 1.97 & 2.00 & 2.02 \\
\hline \multirow{3}{*}{$V / f=9$} & Force $(N)$ & 23.5 & 26.5 & 35.5 & 41.2 & 57.8 & 62.7 & 66.6 & 68.6 & 67.6 & 71.5 \\
\hline & Input Power $(W)$ & 83.49 & 180.29 & 291.61 & 421.08 & 550.55 & 689.70 & 813.12 & 929.28 & 1107.15 & 1196.69 \\
\hline & Flux in a Pole $(W b)$ & 1.04 & 1.48 & 1.63 & 1.65 & 1.72 & 1.78 & 1.83 & 1.90 & 1.95 & 2.05 \\
\hline \multirow[t]{3}{*}{$V / f=10$} & Force $(N)$ & 23.5 & 33.3 & 48.0 & 52.9 & 63.7 & 68.6 & 71.5 & 75.5 & 80.4 & 82.3 \\
\hline & Input Power $(W)$ & 102.85 & 221.43 & 358.16 & 514.25 & 676.39 & 853.05 & 1007.93 & 1149.50 & 1369.72 & 1328.58 \\
\hline & Flux in a Pole $(W b)$ & 1.10 & 1.52 & 1.60 & 1.69 & 1.77 & 1.83 & 1.88 & 1.94 & 2.00 & 1.99 \\
\hline \multicolumn{12}{|c|}{ De-Alignment Test ( for an airgap of $7 \mathrm{~mm}$ at $V / f=9$ ) } \\
\hline \multirow[t]{2}{*}{ Reference Value } & Force $(N)$ & 24.5 & 40.2 & 44.1 & 53.9 & 60.8 & 62.7 & 63.7 & 68.6 & 72.5 & 74.5 \\
\hline & Input Power $(W)$ & 78.65 & 171.82 & 278.30 & 407.77 & 555.39 & 689.70 & 804.65 & 971.63 & 1105.94 & 1292.28 \\
\hline \multirow{2}{*}{$15 \mathrm{~mm}$} & Force $(N)$ & 21.6 & 24.5 & 46.1 & 51.9 & 49.0 & 60.8 & 58.8 & 61.7 & 62.7 & 63.7 \\
\hline & Input Power $(W)$ & 84.70 & 181.50 & 285.56 & 411.40 & 543.40 & 678.81 & 832.48 & 945.01 & 1063.59 & 1213.63 \\
\hline \multirow[t]{2}{*}{$32 \mathrm{~mm}$} & Force $(N)$ & 21.6 & 27.4 & 36.3 & 42.1 & 47.0 & 54.9 & 56.8 & 57.8 & 58.8 & 60.8 \\
\hline & Input Power $(W)$ & 83.49 & 176.66 & 298.87 & 423.50 & 590.48 & 692.12 & 846.16 & 964.37 & 1085.37 & 1211.21 \\
\hline \multicolumn{12}{|c|}{ Electric Circuit Break (for an airgap of $7 \mathrm{~mm}$ at $V / f=9$ ) } \\
\hline \multirow[t]{2}{*}{$9.7 \mathrm{~cm}$} & Force $(N)$ & 13.7 & 25.5 & 28.4 & 38.2 & 42.1 & 41.2 & 43.1 & 46.1 & 48.0 & 49.0 \\
\hline & Input Power $(W)$ & 75.02 & 153.67 & 239.58 & 332.75 & 427.13 & 551.76 & 606.21 & 717.53 & 822.80 & 941.38 \\
\hline \multirow[t]{2}{*}{$20 \mathrm{~cm}$} & Force $(N)$ & 13.7 & 17.6 & 23.5 & 23.5 & 26.5 & 28.4 & 28.4 & 29.4 & 31.4 & 33.3 \\
\hline & Input Power $(W)$ & 77.44 & 146.41 & 216.59 & 285.56 & 358.16 & 428.34 & 490.05 & 551.76 & 626.78 & 664.29 \\
\hline \multirow[t]{2}{*}{$32.4 \mathrm{~cm}$} & Force $(N)$ & 13.7 & 13.7 & 13.7 & 14.7 & 16.7 & 17.6 & 18.6 & 26.5 & 28.4 & 28.4 \\
\hline & Input Power $(W)$ & 76.23 & 135.52 & 181.5 & 227.48 & 280.72 & 317.02 & 373.89 & 404.14 & 463.43 & 492.47 \\
\hline \multicolumn{12}{|c|}{ Magnetic Circuit Break (for an airgap of $7 \mathrm{~mm}$ at $V / f=9$ ) } \\
\hline \multirow[t]{2}{*}{$5.2 \mathrm{~cm}$} & Force $(N)$ & 13.7 & 20.6 & 28.4 & 35.3 & 39.2 & 49.0 & 52.9 & 59.8 & 60.8 & 60.8 \\
\hline & Input Power $(W)$ & 76.23 & 156.09 & 255.3 & 361.79 & 487.63 & 612.26 & 750.20 & 889.35 & 1052.70 & 1228.15 \\
\hline \multirow[t]{2}{*}{$11 \mathrm{~cm}$} & Force $(N)$ & 19.6 & 26.5 & 33.3 & 39.2 & 52.9 & 54.9 & 51.0 & 60.8 & 65.7 & 66.6 \\
\hline & Input Power $(W)$ & 77.44 & 166.98 & 263.78 & 367.84 & 485.21 & 619.52 & 763.53 & 899.03 & 1050.28 & 1211.21 \\
\hline \multirow[t]{2}{*}{$19.5 \mathrm{~cm}$} & Force $(N)$ & 13.7 & 22.5 & 29.4 & 36.3 & 40.2 & 44.1 & 45.1 & 52.9 & 60.8 & 62.7 \\
\hline & Input Power $(W)$ & 83.49 & 175.45 & 275.88 & 382.36 & 506.99 & 627.99 & 765.93 & 901.45 & 1045.44 & 1190.64 \\
\hline \multicolumn{12}{|c|}{ Simultaneous break test (for an airgap of $7 \mathrm{~mm}$ at $\mathrm{V} / \mathrm{f}=9$ ) } \\
\hline \multirow[t]{2}{*}{$6.2 \mathrm{~cm}$} & Force $(N)$ & 13.7 & 24.5 & 33.3 & 36.3 & 40.2 & 44.1 & 47.0 & 50.0 & 48.0 & 51.9 \\
\hline & Input Power $(W)$ & 82.28 & 163.35 & 248.05 & 332.75 & 427.13 & 528.77 & 630.41 & 732.05 & 850.63 & 935.33 \\
\hline \multirow[t]{2}{*}{$17.5 \mathrm{~cm}$} & Force $(N)$ & 13.7 & 19.6 & 26.5 & 28.4 & 33.3 & 36.3 & 38.2 & 42.1 & 46.1 & 50.0 \\
\hline & Input Power $(W)$ & 87.12 & 177.87 & 260.15 & 337.59 & 418.66 & 500.94 & 547.75 & 626.28 & 710.27 & 755.04 \\
\hline
\end{tabular}

\section{BREAK IN SECONDARY CIRCUIT TEST}

The breaks in secondary circuit of LIM are required in order to account for thermal expansion, providing curves in secondary at turns and saving the material cost.

To account for these factors tests have been carried out in three stages.

1) By creating breaks in Electrical circuit by using discontinuous aluminium: Electrical circuit break can be represented by break in the continuation of aluminium sheet. The electric break gap was of three lengths i.e. $9.7 \mathrm{~cm}, 20 \mathrm{~cm}$ and $32.4 \mathrm{~cm}$. Table II show the propulsion force and input power for these three breaks.

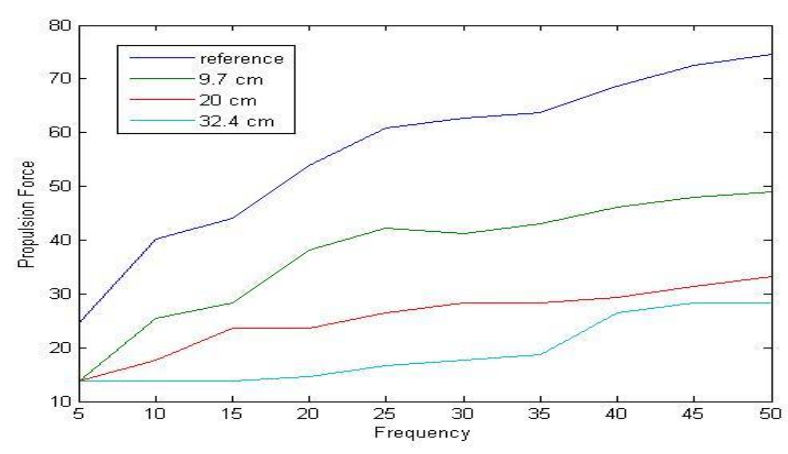

Fig. 7. Propulsion force vs. Frequency for Al Breaks

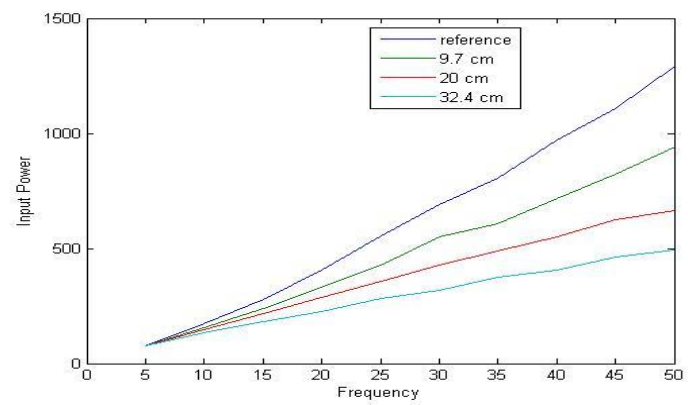

Fig. 8. Input power vs. Frequency for Al Breaks

2) By creating breaks in Magnetic Circuit: Magnetic circuit break can be realized by break in the mild steel (Back Iron).The gap that were introduced are of length $5.2 \mathrm{~cm}, 11 \mathrm{~cm}$ and $19.5 \mathrm{~cm}$. Table II show the propulsion force and input power for the different gaps.

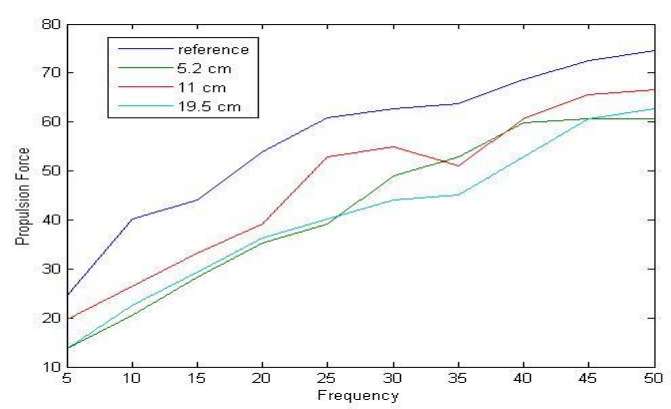

Fig. 9. Propulsion force vs. frequency for mild steel breaks 


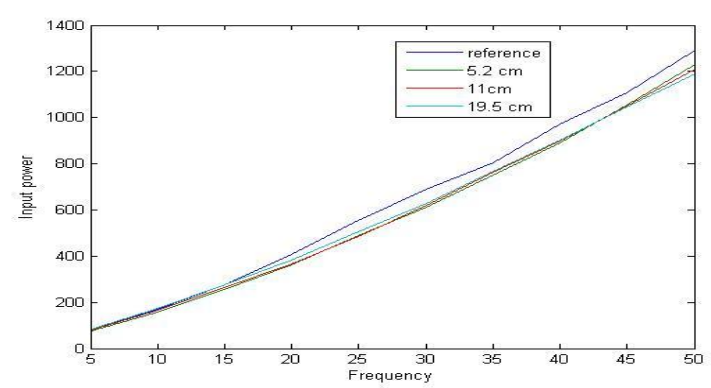

Fig. 10 . Input power vs. frequency for mild steel breaks

3) Simultaneous breaks in electrical and magnetic circuits: The gaps that were introduced are of length $6.2 \mathrm{~cm}$ and $17.5 \mathrm{~cm}$. Table II show the propulsion force and input power for the different gaps.

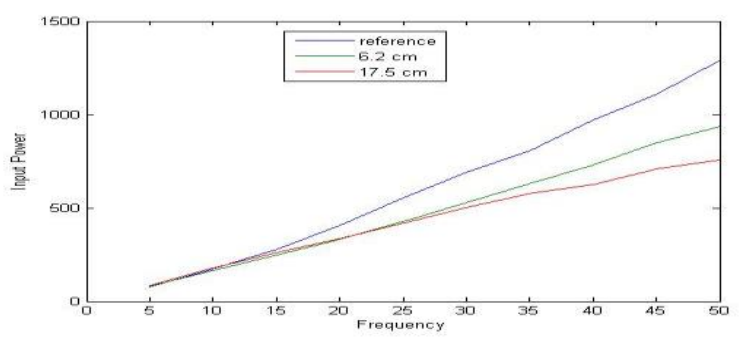

Fig. 11. Propulsion force vs. frequency for reaction rail break

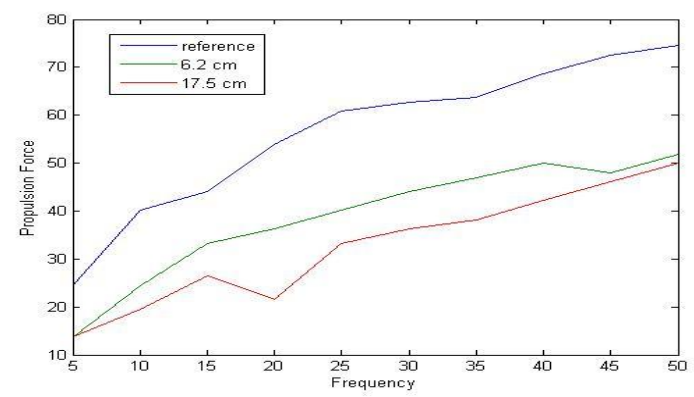

Fig. 12. Input power vs. frequency for reaction rail break

Fig. 7 clearly shows that break in electrical circuit have very predominant effect on the magnitude of propulsion force. As the break length increases the magnitude of propulsion force get reduced sharply. This behavior can be accounted for reduced eddy current due to absence of electrical circuit. This weakens the strength of poles developed on secondary, and thus, above behavior is observed.

The graph in Fig. 9 shows that the reductions in propulsion force due to break in magnetic circuit is not as dominant as due to break in the electrical circuit. This is due to the fact that break in magnetic circuit do not affect the eddy current in Aluminium Plate, so, the strength of magnetic poles are more or less unaffected. The discontinuity in flux path is created due break in magnetic that accounts for reduction in force. If this discontinuity pertains for larger distance then there will certainly a large dip in the magnitude of Propulsion force.

The graph in Fig. 11 Shows that even $10 \%$ of simultaneous break in the Aluminium and Mild-steel cause large reduction in the propulsion force owing to both the effects described above acting together.
Hence, large break in electrical circuit is not desirable as it reduces the propulsion force greatly. But, large breaks in magnetic circuit (up to $30 \%$ of length of LIM primary) can be allowed wherever required. The breaks in electrical circuit should not exceed $10 \%$ of length of LIM primary.

\section{Voltage CONTROL TEST}

Voltage control tests were carried out at constant frequency of $50 \mathrm{~Hz}$. The voltage can be varied from 207 volt to 500 volt using the VVVF drive. Data were obtained for three different air gaps of $9 \mathrm{~mm}, 7 \mathrm{~mm}$ and $5 \mathrm{~mm}$ between primary and secondary of LIM. Table III. Shows the experimental data obtained for airgap of $9 \mathrm{~mm}$

TABLE III: AT F=50 Hz: POWER, POLE FLUX AND PROPULSION FORCE FOR

\begin{tabular}{|c|c|c|c|c|c|c|c|c|}
\hline \multicolumn{9}{|c|}{ AIRGAP OF 9MM } \\
\hline Airgap & Voltage & 207 & 250 & 300 & 350 & 400 & 450 & 500 \\
\hline \multirow{3}{*}{$5 \mathrm{~mm}$} & $\operatorname{Force}(N)$ & 27.4 & 29.4 & 45.1 & 48.0 & 63.7 & 80.4 & 85.3 \\
\hline & $\begin{array}{c}\text { Input } \\
\text { Power, } W\end{array}$ & 260 & 350 & 570 & 799 & 1045 & 1290 & 1515 \\
\hline & $\begin{array}{l}\text { Flux in a } \\
\text { Pole (Wb) }\end{array}$ & 1.88 & 1.95 & 2.01 & 2.08 & 2.13 & 2.20 & 2.20 \\
\hline \multirow{3}{*}{$7 \mathrm{~mm}$} & $\operatorname{Force}(N)$ & 21.6 & 24.5 & 34.3 & 44.1 & 66.4 & 72.5 & 83.3 \\
\hline & $\begin{array}{c}\text { Input } \\
\text { Power, } W\end{array}$ & 242 & 358 & 560 & 763 & 981 & 1257 & 1519 \\
\hline & $\begin{array}{l}\text { Flux in a } \\
\text { Pole }(W b)\end{array}$ & 1.93 & 2.0 & 2.06 & 2.14 & 2.18 & 2.24 & 2.24 \\
\hline \multirow{3}{*}{$9 m m$} & Force $(N)$ & 17.6 & 25.5 & 36.3 & 47.0 & 52.9 & 66.6 & 78.4 \\
\hline & $\begin{array}{c}\text { Input } \\
\text { Power, } W\end{array}$ & 243 & 353 & 523 & 728 & 956 & 1215 & 1481 \\
\hline & $\begin{array}{l}\text { Flux in a } \\
\text { Pole }(W b)\end{array}$ & 1.98 & 2.04 & 2.11 & 2.17 & 2.22 & 2.28 & 2.27 \\
\hline
\end{tabular}

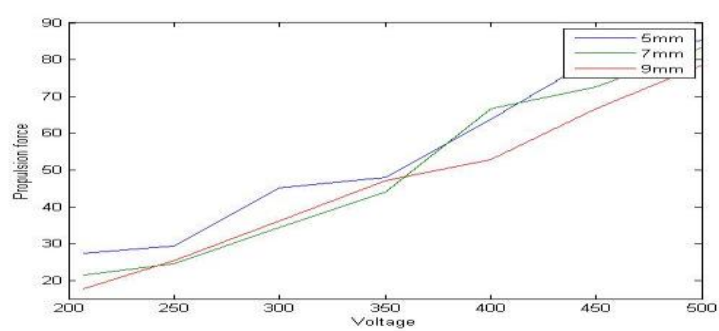

Fig. 13. Propulsion force variation with voltage for different airgap

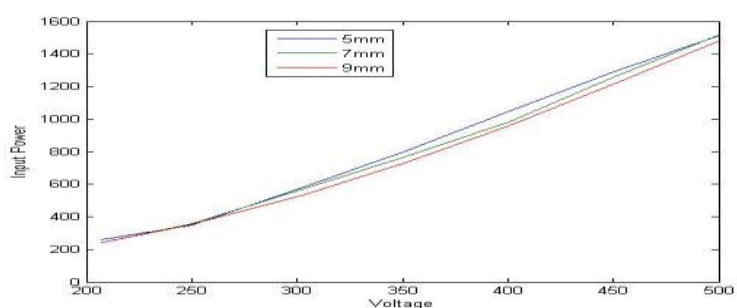

Fig. 14. Input power variation with voltage for different airgap

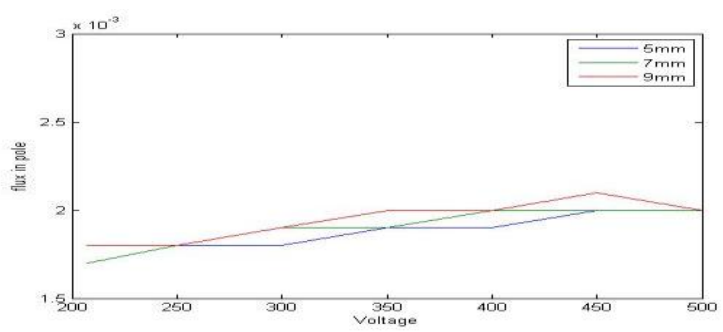

Fig.15. Flux in a pole variation with voltage for different airgap

In Fig. 15. The variation of flux in pole with respect to 
secondary can be seen for different air gaps. It is observed that, flux is increasing in the pole with the increasing voltage. As the flux produced in pole by is proportional to the ratio of voltage and the operating frequency of the supply. The relation is shown in equation (1).

$$
\Phi=\frac{1}{\sqrt{2} \pi k N} \cdot\left(\frac{V}{f}\right)
$$

Hence, if the starting will be done at rated voltage or if high voltage will be applied to obtain large starting torque, it will cause saturation of mild steel core of LIM. So, constant V/f control gives a better solution where starting can be done at lower frequency and hence higher starting torque can be obtained at wide range of initial speed.

\section{CONCLUSIONS}

This paper has investigated Static performance characteristics of a single sided LIM fabricated to drive a LIMP Metro Model developed at IRIEEN, Nasik, under standstill condition. Experiments were performed by developing a static test bed on the testing track. The results obtained from the test supports the advantages of application of LIM in modern metros. It will help in carrying out the further investigation in starting of LIM based drive.

\section{ACKNOWLEDGEMENT}

The author expresses his sincere gratitude to Dr. S. N. Mahendra for his valuable support and guidance during design, fabrication and planning of these tests. He is also thankful to Mr.V.K.Dutt, Additional Member Electrical Railway Board, Indian Railway for his interest and making it possible for him to work in IRIEEN, Nasik. Special thanks owe to the Mr.D.Ramaswamy, Director, IRIEEN and all the professors of Indian railway Institute of Electrical Engineering, Nasik, who generously helped at all steps of fabrication and testing by providing necessary technical and financial support. He would like to thank his friends Raj Kumar Sinha, Pritesh Kumar, Rajeev Sisodia and Ram Gopal Varma for their constant help and support in carrying out the experiment.

\section{REFERENCES}

[1] S. N. Mahendra, Reports of AICTE funded Project on LIM at IT BHU,1994-1999.

[2] S. N. Mahendra, "LIM based traction :philosophy, selection,design aspects and applicationto transport sector," International Workshop on LIM propelled rail Metro System, Banaras Hindu University, Varanasi, India, Jan. 8-9 1999

[3] Y. Cho, "An Investigation on the Characteristics of a Single-sided Linear Induction Motor at Standstill for Maglev Vehicle," IEEE Transactions On Magnetics, vol. 33, no. 2, March 1997.

[4] J. Upadhyay and S. N. Mahendra, Eleectric Traction, Allied publishers Ltd., New Delhi, 2000. 